\title{
Precise manipulation of electron transfers in clustered five redox sites
}

Hitoshi Izu, ${ }^{1,2,3,4}$ Mio Kondo, ${ }^{1,2,5,6}$ Masaya Okamura, ${ }^{2}$ Misa Tomoda, ${ }^{1,2,3}$ Sze Koon Lee, ${ }^{2}$ Takuya Akai, ${ }^{1}$ Vijayendran K. K. Praneeth, ${ }^{2,7}$ Mari Kanaike, ${ }^{2}$ Satoshi Kawata ${ }^{8}$ and Shigeyuki Masaoka*1,2,5

${ }^{1}$ Division of Applied Chemistry, Graduate School of Engineering, Osaka University, 2-1 Yamadaoka, Suita Osaka 565-0871, Japan.

${ }^{2}$ Department of Life and Coordination-Complex Molecular Science, Institute for Molecular Science, Higashiyama 5-1, Myodaiji, Okazaki, Aichi 444-8787, Japan.

${ }^{3}$ SOKENDAI (The Graduate University for Advanced Studies), Shonan Village, Hayama, Kanagawa 240-0193, Japan.

${ }^{4}$ AIST-Kyoto University Chemical Energy Materials Open Innovation Laboratory (ChEM-OIL), National Institute of Advanced Industrial Science and Technology (AIST), Kyoto 606-8501, Japan

${ }^{5}$ Innovative Catalysis Science Division, Institute for Open and Transdisciplinary Research Initiatives (ICS-OTRI), Osaka University, Suita, Osaka 565-0871, Japan.

${ }^{6}$ PRESTO, Japan Science and Technology Agency (JST), 4-1-4 Honcho, Kawaguchi, Saitama 332-0012, Japan.

${ }^{7}$ Department of Chemistry, Kalasalingam Academy of Research and Education (KARE), Anand Nagar, Krishnankoil, 626126 Tamil Nadu, India.

${ }^{8}$ Department of Chemistry, Faculty of Science, Fukuoka University, Nanakuma, Jonanku 8-19-1, Fukuoka 814-0180, Japan. 


\section{Abstract}

Electron transfers in multinuclear metal complexes are the origin of their unique functionalities both in natural and artificial systems. However, electron transfers in multinuclear metal complexes are generally complicated, and predicting and controlling these electron transfers is extremely difficult. Herein, we report the precise manipulation of the electron transfers in multinuclear metal complexes. The development of a rational synthetic strategy afforded a series of pentanuclear metal complexes composed of metal ions and 3,5-bis(2-pyridyl)pyrazole (Hbpp) as a platform to probe the phenomena. Electrochemical and spectroscopic investigations clarified the overall picture of the electron transfers in the pentanuclear complexes. In addition, unique electron transfer behaviours, in which the reduction of a metal centre occurs during the oxidation of the overall complex (reduction-upon-oxidation process), were discovered. We also elucidated the two dominant factors that determine the manner of the electron transfers. Our results provide comprehensive guidelines for interpreting the complicated electron transfers in multinuclear metal complexes. 


\section{Introduction}

Multinuclear metal complexes are an intriguing class of materials due to not only their fascinating structures ${ }^{1-9}$ but also their unique redox ${ }^{10-15}$, magnetic ${ }^{16-18}$ and photochemical properties ${ }^{19,20}$ and reactivity ${ }^{21-26}$. Due to these attractive properties, multinuclear metal complexes play a significant role in several biological systems ${ }^{27-30}$ and are expected to be functional materials for future practical applications ${ }^{31-34}$ (Scheme 1a). An important feature of this class of materials is their ability to access various electronic states via electron transfer reactions, and the formed species display distinct electronic structures with unique chemical and physical properties. For instance, in reactions catalysed by natural metalloenzymes, the existence of several species with distinct electronic states substantially promotes the efficiency of these reactions. ${ }^{35}$ Therefore, controlling electron transfers in multinuclear metal complexes can be an important strategy for obtaining target functional materials. However, the redox behaviours of these complexes are generally complicated due to the existence of several possible electron transfer pathways (Scheme 1b). Additionally, the nature, arrangement, and coordination environment of the metal ions can also alter the electron transfer behaviours. These factors make predicting and controlling electron transfers in multinuclear metal complexes extremely difficult. 
a) Multinuclear Metal Complexes

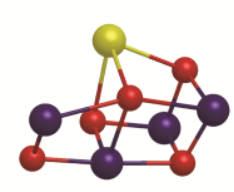

OEC

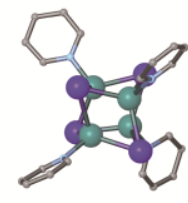

Photochemistry

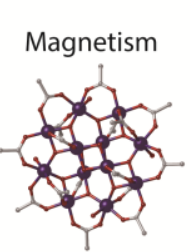

Sophisticated electron transfer enables excellent functions

b) Electron Transfer in Multinuclear Metal Complexes
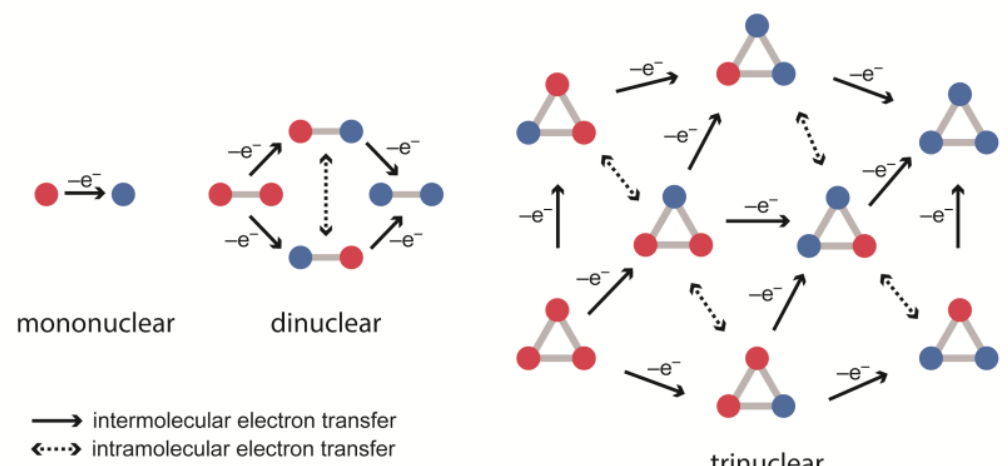

trinuclear

\section{Difficult to control/understand electron transfer reactions}

c) This Work
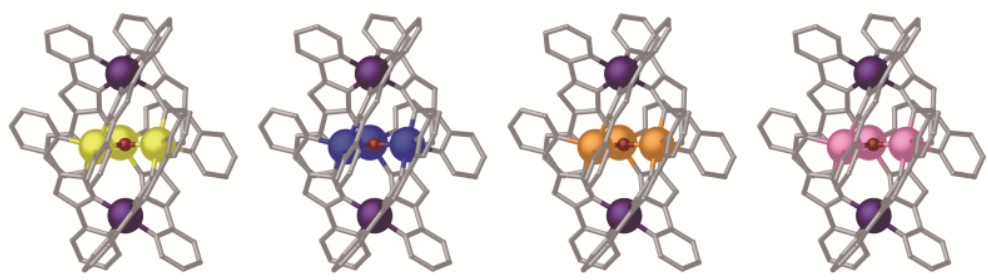

Precise manipulation of electron transfer in multinuclear complexes

Scheme 1 | (a) Representative examples and functions of multinuclear metal complexes in natural and artificial systems. (b) Schematic representation of the electron transfer reactions in multinuclear metal complexes. Red and blue circles denote the reduced and oxidized cores, respectively. As the number of redox cores increases, the redox behaviours become more complicated, which makes predicting/controlling the electron transfers increasingly difficult. (c) Summary of this work. 
The systematic investigation on a series of multinuclear metal complexes is of great significance to elucidate factors that determine the manner of electron transfers. Particularly, a series of multinuclear metal complexes, in which different kinds of metal ions are installed into the same molecular framework, is an excellent candidate to minimize the effect of unrelated components. However, on-demand installation of the metal ions into the desired multinuclear structure is still challenging and this synthetic difficulty hampers the construction of definitive matrix to manipulate the electron transfers of multinuclear metal complexes.

In this study, we constructed a novel platform to probe the electron transfers in multinuclear metal complexes (Scheme 1c). A rational procedure to enable on-demand installation of metal ions utilizing a stepwise synthetic method was developed, and this process affords a series of multinuclear complexes that have different arrangement of metal ions while maintaining the same molecular framework. The global investigation of the redox behaviours of the obtained multinuclear metal complexes clarified that flexible electron transfer processes in redox cores afford various chemical species with distinct electronic states, and these processes are largely dependent on the arrangement of metal ions. Moreover, our systematic investigation resulted in the extraction of the dominant 
factors that impact these electron transfers. As a result, guidelines for manipulating electron transfers in multinuclear metal complexes were successfully developed. 


\section{Results and discussion}

\section{Strategy}

Our study started with the development of a rational synthetic strategy that enables the on-demand installation of metal ions into multinuclear metal complexes. As the molecular scaffold, we focused on a pentanuclear complex composed of 3,5-bis(2pyridyl)pyrazole (Hbpp) and metal ions. Electronic interactions occur among the metal ions in this class of complexes, and these interactions afford unique electronic $^{36,37} / \operatorname{spin}^{38,39}$ states and catalytic activities ${ }^{25,40,41,42,43}$. To assemble metal ions into this pentanuclear scaffold in a controlled fashion, we developed the new stepwise synthetic method shown in Scheme 2. In our strategy, a relatively substitution-inert metal ion (M) is initially reacted with Hbpp under harsh conditions to afford a mononuclear complex, $\left[\mathbf{M}(\mathbf{H b p p})_{3}\right]^{\mathbf{n}+}$. Subsequently, $\left[\mathbf{M}(\mathbf{H b p p})_{3}\right]^{\mathbf{n}+}$ is reacted with a relatively substitution-labile metal ion (M') under milder conditions. This strategy suppresses the scrambling of the metal ions and affords pentanuclear complexes with the desired arrangement of metal ions. In this study, a ruthenium ion was selected as M because ruthenium-based complexes display redox activity, and their absorption properties are highly depended on their oxidation states ${ }^{44}$, making them suitable for probing the electronic structures of the generated complexes. A series of first-row transition metal 
ions with different redox activities (zinc, cobalt, iron, and manganese ions) were employed as M'. Notably, the large difference in the number of electrons in $\mathrm{M}$ and $\mathrm{M}^{\prime}$ should allow the determination of the arrangement of the metal ions in the obtained complexes by X-ray crystallographic techniques.
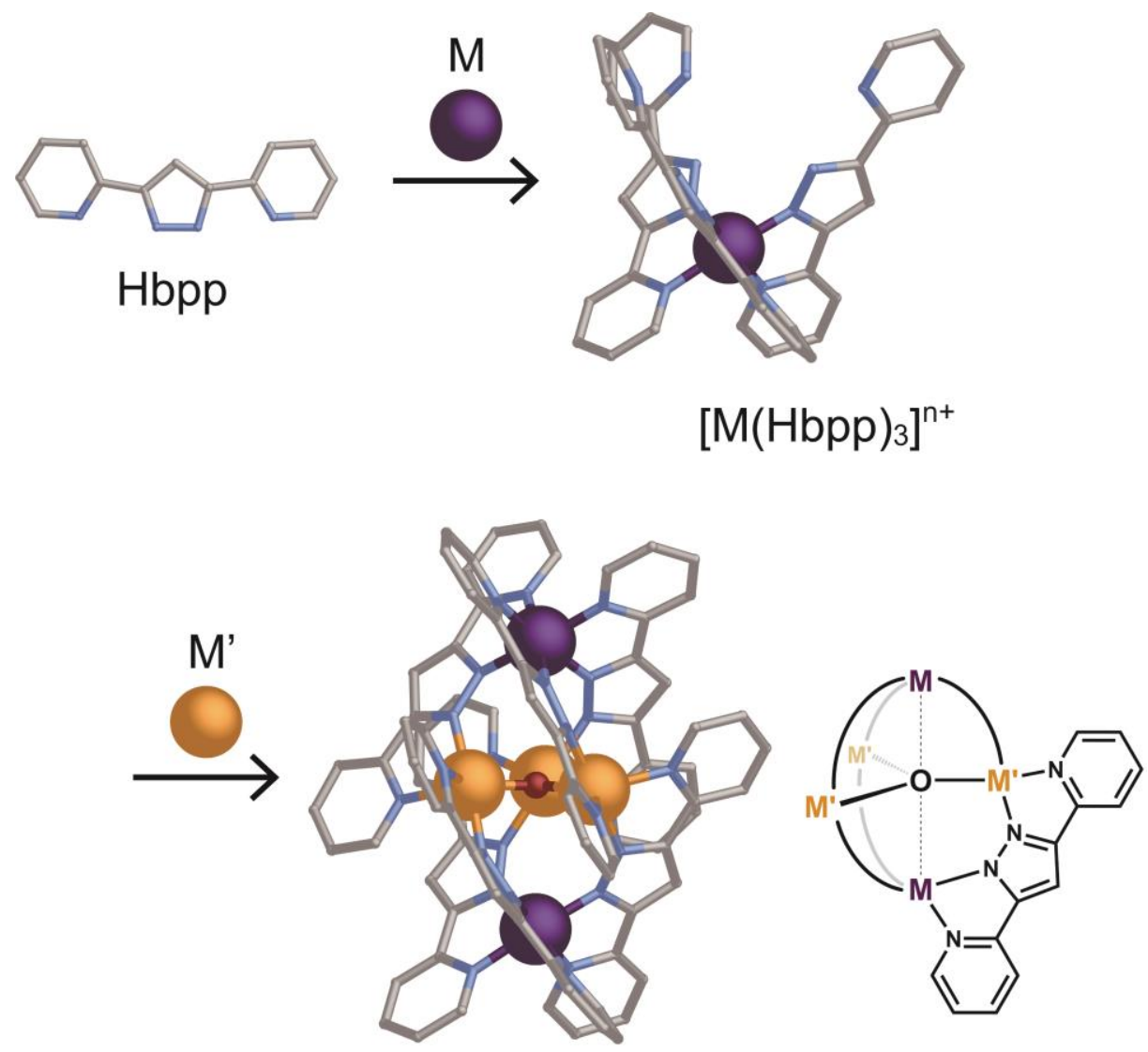

$\mathbf{M}_{2} \mathbf{M}_{3}$

Scheme 2 Synthetic strategy for obtaining a series of heterometallic pentanuclear complexes. $\mathrm{M}_{1}$ and $\mathrm{M}_{2}$ represent substitution-inert and substitution-labile metal ions, respectively. 


\section{Synthesis and characterization}

A mononuclear ruthenium complex was synthesized by reacting $\mathrm{RuCl}_{3}$ with Hbpp at $120^{\circ} \mathrm{C}$, and the desired complex, $\left[\mathbf{R u}(\mathbf{H b p p})_{3}\right]\left(\mathrm{ClO}_{4}\right)_{2}$, was obtained in $13 \%$ yield (Electronic Supplementary Information (ESI) for synthetic details). Subsequently, $\left[\mathbf{R u}(\mathbf{H b p p})_{3}\right]\left(\mathrm{ClO}_{4}\right)_{2}$ was reacted with the appropriate first-row metal ion at $80-100{ }^{\circ} \mathrm{C}$ (for synthetic details, see the ESI). The yields for the second step were in the range of 72$85 \%$, indicating the selective formation of a series of heterometallic pentanuclear complexes. We also prepared the relevant homometallic pentanuclear complexes, $\left[\left\{\mathrm{Zn}^{\mathrm{II}}(\mu-\mathrm{bpp})_{3}\right\}_{2} \mathrm{Zn}_{3}{ }_{3}(\mu-\mathrm{OH})\right]^{3+}(\mathbf{Z n} \mathbf{5}),\left[\left\{\mathrm{Co}^{\mathrm{II}}(\mu-\mathrm{bpp})_{3}\right\}_{2} \mathrm{Co}_{3}{ }_{3}(\mu-\mathrm{OH})\right]^{3+}(\mathbf{C o s}),\left[\left\{\mathrm{Fe}^{\mathrm{II}}(\mu-\right.\right.$ bpp $\left.\left.)_{3}\right\}_{2} \mathrm{Fe}^{\mathrm{II}}{ }_{2} \mathrm{Fe}^{\mathrm{III}}(\mu-\mathrm{O})\right]^{3+}(\mathbf{F e} 5)$, and $\left[\left\{\mathrm{Mn}^{\mathrm{II}}(\mu-\mathrm{bpp})_{3}\right\}_{2} \mathrm{Mn}_{2}{ }_{2} \mathrm{Mn}^{\mathrm{III}}(\mu-\mathrm{O})\right]^{3+}$ (Mns) (see the ESI for synthetic details). All the complexes were characterized by ESI-TOF-MS, elemental analysis, and single-crystal X-ray diffraction.

The crystal structures of the hetero/homometallic pentanuclear complexes are shown in Figure 1 and Supplementary Figure 3, and the crystallographic data are summarized in Supplementary Tables 2 and 3. All the complexes exhibit the desired pentanuclear structures with quasi- $D_{3}$ symmetry and consist of a triangular core wrapped by two $\left[\mathrm{M}(\mu-\mathrm{bpp})_{3}\right]$ units. The two metal ions at the apical positions $\left(\mathrm{M}_{\mathrm{api}}\right)$ are hexacoordinate with distorted octahedral geometry, whereas the three metal ions in the 
triangular core $\left(\mathrm{M}_{\text {core }}\right)$ are pentacoordinate with distorted trigonal bipyramidal geometry. The bond distances between $\mathrm{M}_{\mathrm{api}}$ and the nitrogen atoms of the $\left[\mathrm{M}(\mu-\mathrm{bpp})_{3}\right]$ units $\left(d\left(\mathrm{M}_{\mathrm{api}}{ }^{-}\right.\right.$ $\mathrm{N})$ ) in the newly synthesized heterometallic complexes are significantly different from those in the corresponding homometallic complexes (Supplementary Tables 4 and 5). In contrast, $d\left(\mathrm{M}_{\mathrm{api}} \mathrm{-}\right)$ are almost constant in the heterometallic complexes. These observations strongly indicate that $\mathrm{M}_{\mathrm{api}}$ in these heterometallic pentanuclear complexes are ruthenium ions. The bond distances between $\mathrm{M}_{\text {core }}$ and the nitrogen atoms in the triangular core $\left(d\left(\mathrm{M}_{\text {core }}-\mathrm{N}\right)\right)$ are similar in the heterometallic and homometallic pentanuclear complexes containing the same first-row transition metal ions. Moreover, the bond distances between $\mathrm{M}_{\text {core }}$ and the oxygen atom in the triangular core $\left(d\left(\mathrm{M}_{\text {core }}-\mathrm{O}\right)\right)$ of the heterometallic complexes are quite similar to those in the corresponding homometallic complexes. Thus, the structures of the triangular cores in the heterometallic and homometallic complexes are identical. Taken together, the structures of the heterometallic pentanuclear complexes in this series can be described as $\left[\left\{\mathrm{Ru}^{\mathrm{II}}(\mu-\right.\right.$ bpp $\left.\left.)_{3}\right\}_{2} \mathrm{Zn}_{3}{ }_{3}(\mu-\mathrm{OH})\right]^{3+}\left(\mathbf{R u} \mathbf{Z n}_{3}\right),\left[\left\{\mathrm{Ru}^{\mathrm{II}}(\mu-\mathrm{bpp})_{3}\right\}_{2} \mathrm{Co}_{3}{ }_{3}(\mu-\mathrm{OH})\right]^{3+}\left(\mathbf{R u} \mathbf{C u}_{2} \mathbf{C o 3}\right),\left[\left\{\mathrm{Ru}^{\mathrm{II}}(\mu-\right.\right.$ bpp $\left.\left.)_{3}\right\}_{2} \mathrm{Fe}^{\mathrm{II}}{ }_{2} \mathrm{Fe}^{\mathrm{III}}(\mu-\mathrm{O})\right]^{3+}\left(\mathbf{R u}_{2} \mathbf{F e} e_{3}\right)$, and $\left[\left\{\mathrm{Ru}^{\mathrm{II}}(\mu-\mathrm{bpp})_{3}\right\}_{2} \mathrm{Mn}^{\mathrm{II}}{ }_{2} \mathrm{Mn}^{\mathrm{III}}(\mu-\mathrm{O})\right]^{3+}\left(\mathbf{R u}_{2} \mathbf{M n}_{3}\right)$. These results indicate that pentanuclear complexes with the desired arrangements of metal ions were successfully synthesized by the stepwise synthetic strategy. 
a (i)
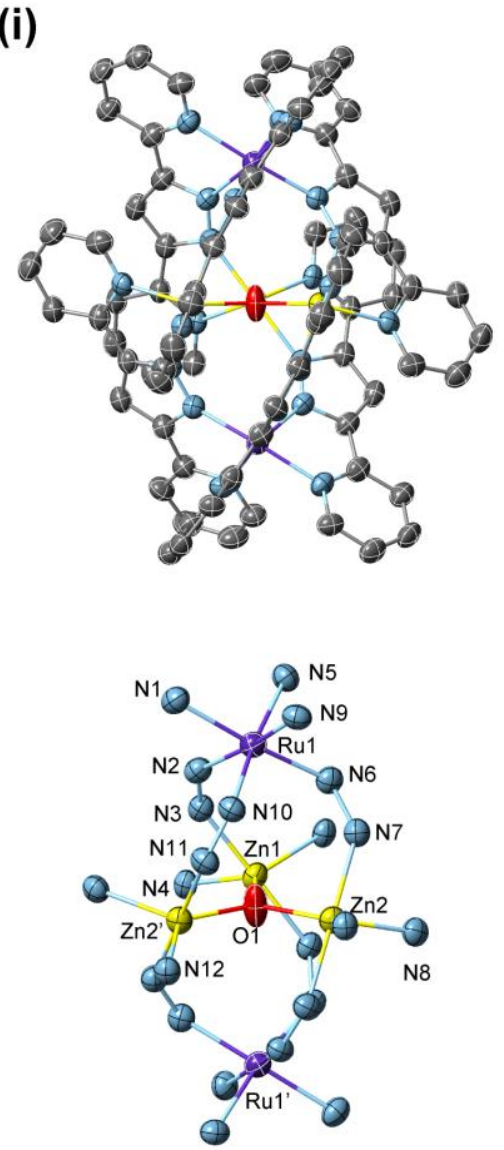

(ii)
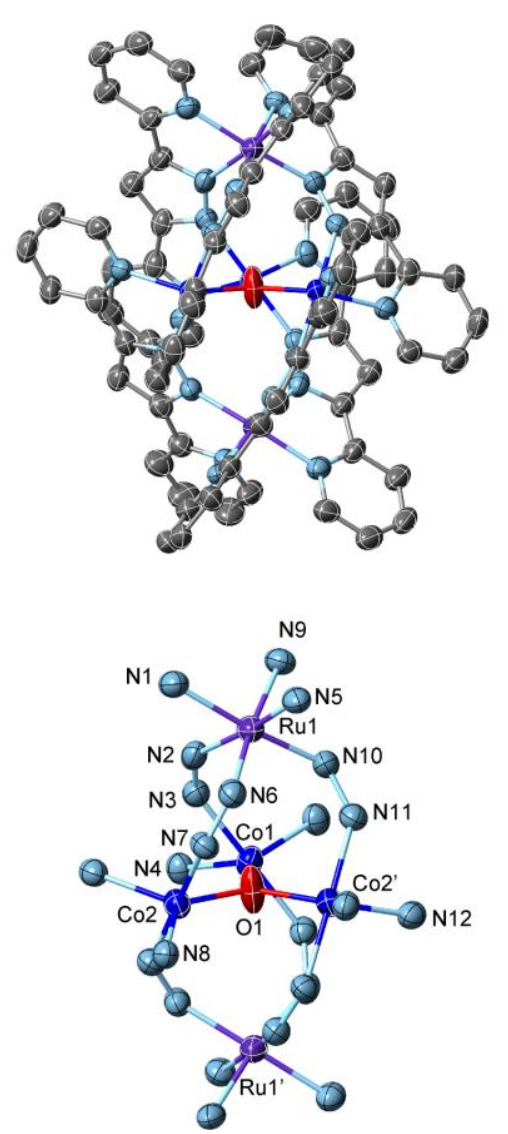

(iii)
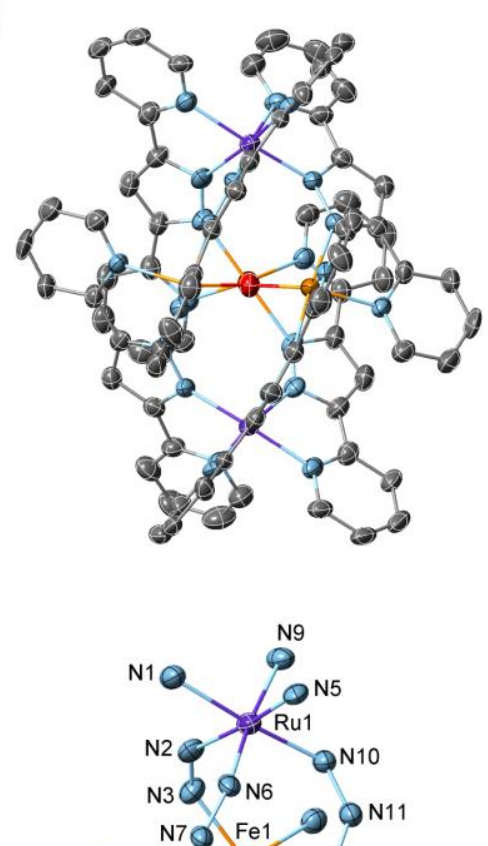

- ${ }^{\mathrm{N}}{ }^{-} \mathrm{F}^{\mathrm{Fe} 1} \rho{ }^{\mathrm{N}}$

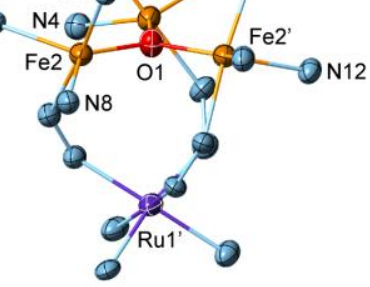

(iv)
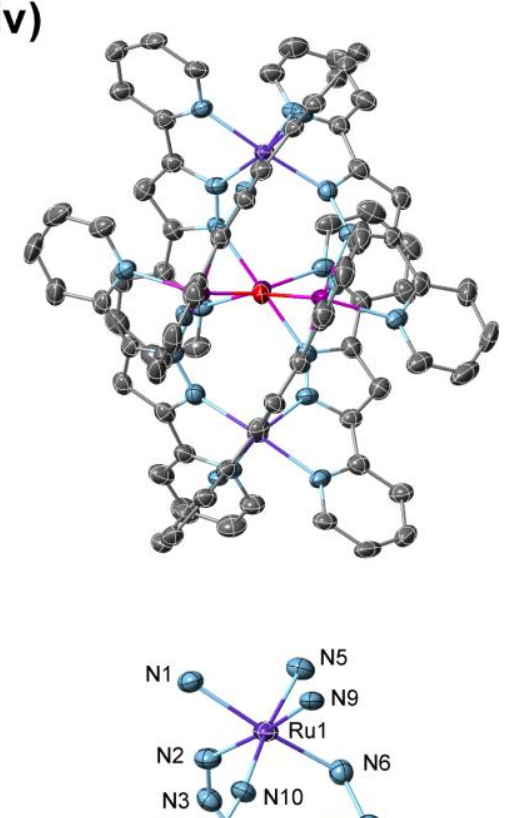

N3 1 N10

N110 Mn1 9 N7 $^{2}$

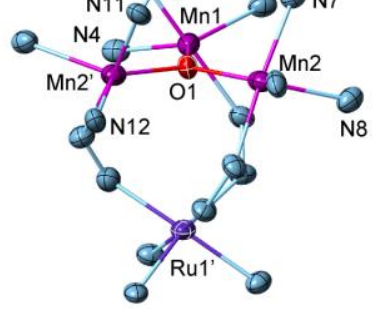

Figure 1 | ORTEP drawings of the cationic moieties (top) and core structures (bottom) of a series of (a) heterometallic ((i) $\mathbf{R u}_{2} \mathbf{Z n}_{3}\left(\mathrm{ClO}_{4}\right)_{3}$,

(ii) $\mathbf{R u}_{2} \mathbf{C o}_{3}\left(\mathrm{PF}_{6}\right)_{3}$, (iii) $\mathbf{R u}_{2} \mathbf{F e}_{3}\left(\mathrm{ClO}_{4}\right)_{3}$, and (iv) $\left.\mathbf{R u}_{2} \mathbf{M n}_{3}\left(\mathrm{ClO}_{4}\right)_{3}\right)$ and (b) homometallic ((i) $\mathbf{Z n}_{5}\left(\mathrm{BF}_{4}\right)_{3}$, (ii) $\mathbf{C o}_{5}\left(\mathrm{BF}_{4}\right)_{3}$, (iii) $\mathbf{F e}_{5}\left(\mathrm{BF}_{4}\right)_{3}$, and 
(iv) $\left.\mathrm{Mn}_{5}\left(\mathrm{ClO}_{4}\right)_{3}\right)$ pentanuclear complexes (50\% probability ellipsoids). Hydrogen atoms are omitted for clarity. $\mathrm{O}=\mathrm{red}, \mathrm{C}=$ grey, $\mathrm{N}=$ pale blue, $\mathrm{Zn}=$ yellow, $\mathrm{Co}=$ blue, $\mathrm{Fe}=$ orange and $\mathrm{Mn}=$ magenta. 
b (i)
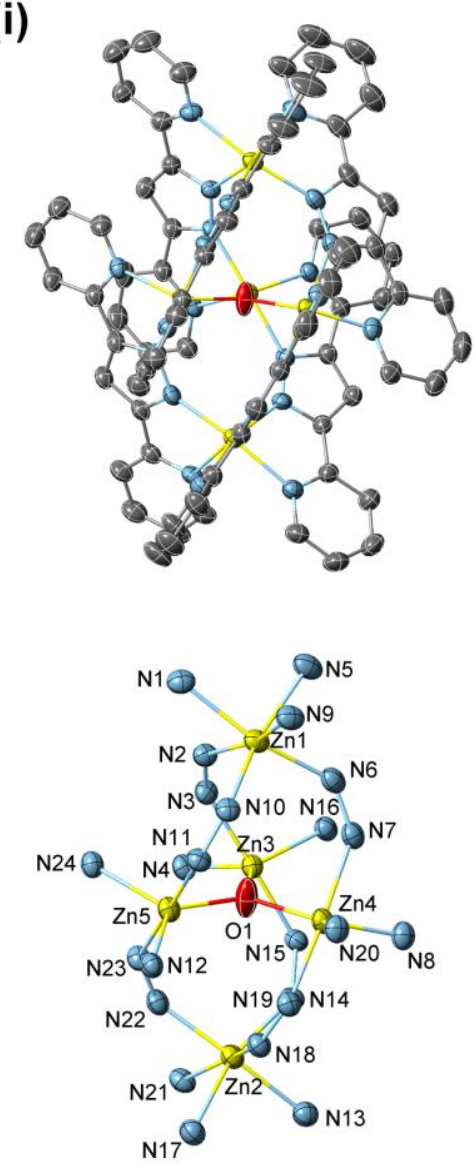

(ii)
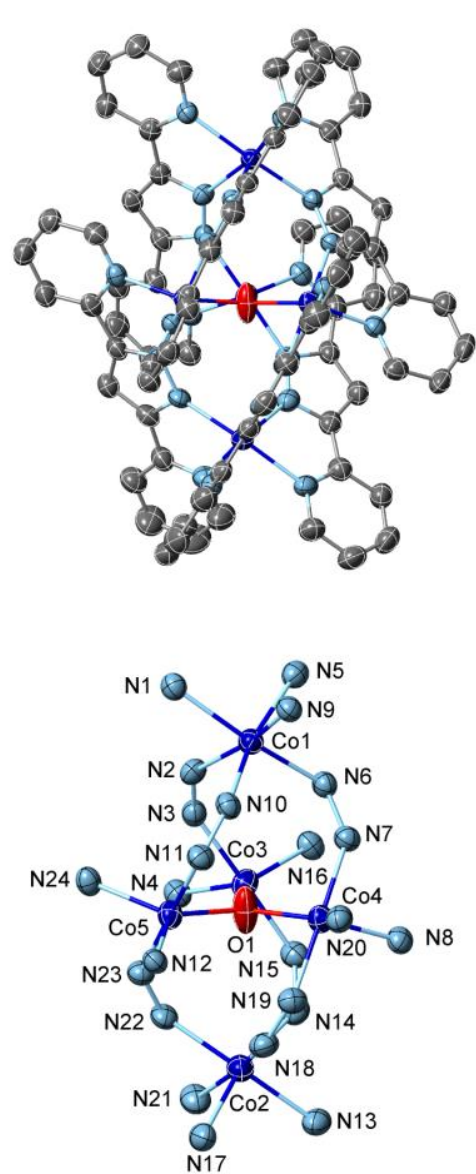

(iii)
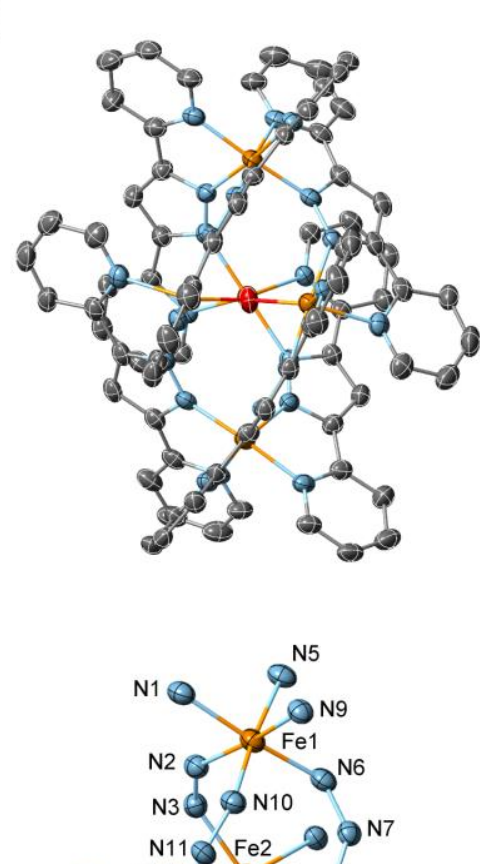

- ${ }^{\mathrm{N} 4} \mathrm{Fe}^{\mathrm{N} 2} \mathrm{P}$

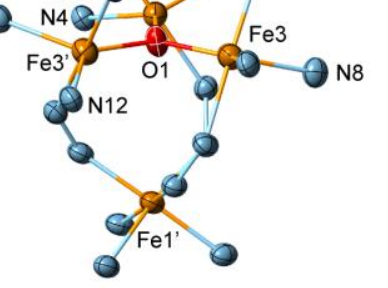

(iv)
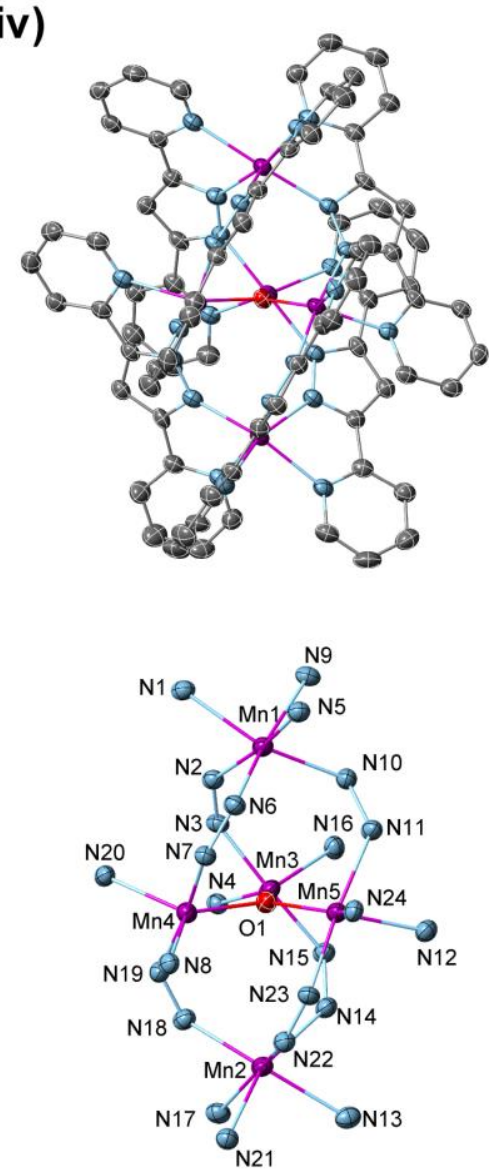

Figure 1 | (Continued) 


\section{Redox behaviours of the pentanuclear metal complexes}

Electrochemical measurements of the series of pentanuclear complexes were made to elucidate their redox behaviours. Although no redox waves were observed in $\mathbf{Z n} 5$ due to the redox inactivity of zinc ions, all other complexes displayed several redox waves reflecting the number of redox-active centres (Figure 2 and Supplementary Table 6). Therefore, all redox waves can be regarded as one-electron transfer processes. $\mathbf{R u}_{2} \mathbf{Z n}_{3}$ exhibited two reversible redox waves at $E_{1 / 2}=0.35$ and $0.51 \mathrm{~V}$ (vs. ferrocene/ferrocenium $\left.\left(\mathrm{Fc} / \mathrm{Fc}^{+}\right)\right)$, and these waves were attributed to the sequential oxidation of the ruthenium ions at the apical positions. In the $\mathrm{CVs}$ of $\mathbf{R u}_{2} \mathbf{C o s}$ and $\mathbf{C o 5}$, two reversible oxidation and three reversible reduction waves were observed. The $E_{1 / 2}$ values of the oxidation waves of $\mathbf{R u}_{2} \mathbf{C o 3}(0.36$ and $0.52 \mathrm{~V})$ are almost identical to those of $\mathbf{R} \mathbf{u}_{2} \mathbf{Z n} 3$, indicating that these can be attributed to the oxidation of the ruthenium ions. The redox potentials of the reduction waves of $\mathbf{R u}_{2} \mathbf{C o s}$ and $\mathbf{C o s}$ were also quite similar $\left(E_{1 / 2}=-1.71,-1.98\right.$, and $-2.24 \mathrm{~V}$ for $\mathbf{R} \mathbf{u}_{2} \mathbf{C o 3}$ and $-1.72,-1.96$, and $-2.19 \mathrm{~V}$ for $\left.\mathbf{C o 5}\right)$, and thus, these waves are assignable to the reduction of the cobalt ions in the triangular core. Accordingly, the oxidation waves of $\mathbf{C o 5}$ at -0.42 and $-0.31 \mathrm{~V}$ were assigned as the oxidation of the Co ions at the apical positions. The $\mathrm{CVs}$ of $\mathbf{R u}_{2} \mathbf{F e}_{3}$ exhibited one reversible reduction wave $\left(E_{1 / 2}=-0.52 \mathrm{~V}\right)$ and four reversible oxidation waves $\left(E_{1 / 2}=0.17,0.56,0.75\right.$, and $\left.1.10 \mathrm{~V}\right)$. 
Although the redox waves corresponding to the oxidation of the ruthenium ions were observed potentials similar to those of $\mathbf{R u}_{2} \mathbf{Z n}_{3}$ and $\mathbf{R u}_{2} \mathbf{C o 3}$ (vide supra), the oxidation potentials of $\mathbf{R u}_{2} \mathbf{F e} 3$ were not located in the same region. In addition, when comparing the redox behaviours of $\mathbf{R u}_{2} \mathbf{F e}_{3}$ and $\mathbf{F e} 5$, only the potential of the second oxidation wave was substantially different, and it had shifted to a more positive value $\left(E_{1 / 2}=0.56 \mathrm{~V}\right.$ for $\mathbf{R u}_{2} \mathbf{F e}_{3}$ and 0.29 V for Fes). Similarly, $\mathbf{R} \mathbf{u}_{2} \mathbf{M n}_{3}$ exhibited one reversible reduction wave at $E_{1 / 2}=-0.65 \mathrm{~V}$ and four sequential oxidation waves at $E_{1 / 2}=0.09,0.58,0.78$, and 1.19 $\mathrm{V}$, and the observed waves were not in regions similar to those of the waves of $\mathbf{R u}_{2} \mathbf{Z n}_{3}$ and $\mathbf{R u}_{2} \mathrm{Cos}_{3}$. In the case of $\mathbf{R u}_{2} \mathbf{M n}_{3}$, however, only the potential of the third oxidation wave was shifted to a more negative potential $\left(E_{1 / 2}=0.78 \mathrm{~V}\right)$ compared to that of Mns $\left(E_{1 / 2}=1.11 \mathrm{~V}\right)$, and this behaviour is different from that of $\mathbf{R} \mathbf{u}_{2} \mathbf{F e}$. These observed redox behaviours of $\mathbf{R u}_{2} \mathbf{F e}_{3}$ and $\mathbf{R u}_{2} \mathbf{M n}_{3}$ imply that the electronic interactions between the different kinds of metal ions alter the nature of the electron transfers. These results prompted us to further explore the redox behaviours of these complexes. 

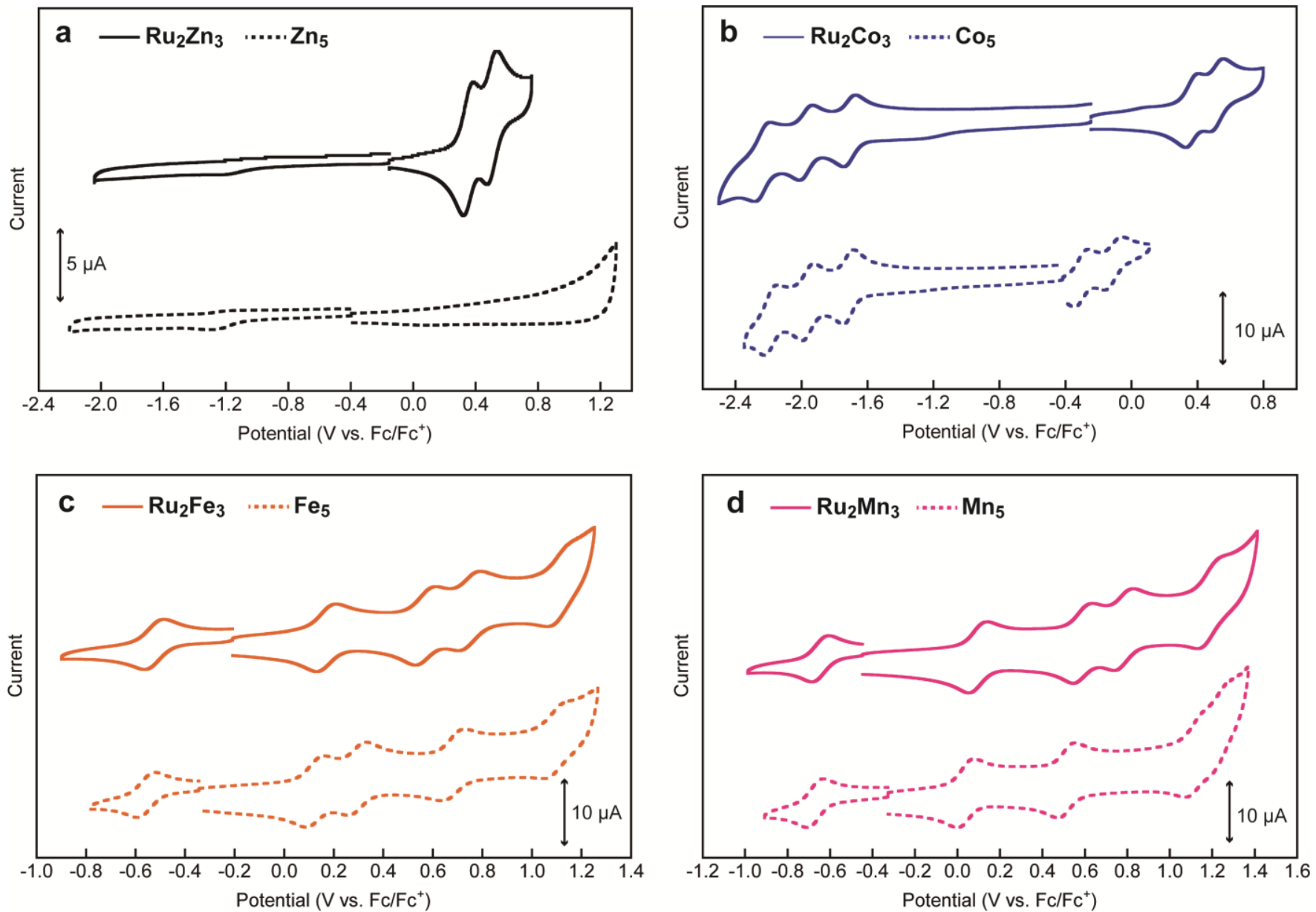

Figure 2 | Cyclic voltammograms of a series of heterometallic (solid lines) and homometallic (dashed lines) pentanuclear metal complexes

$(0.2 \mathrm{mM})$ in acetonitrile solutions containing $(n-\mathrm{Bu})_{4} \mathrm{NClO}_{4}(\mathrm{TBAP}, 0.1 \mathrm{M})$ at a scan rate of $100 \mathrm{mV} / \mathrm{s}$; (a) $\mathbf{R} \mathbf{u}_{2} \mathbf{Z n}_{3}$ and $\mathbf{Z n} 5$, (b) $\mathbf{R u} \mathbf{C u}_{2}$ and $\mathrm{Co5}_{5}$, (c) Ru2Fe3 and Fes, and (d) Ru2Mn3 and Mns. 


\section{Electron transfers in the pentanuclear complexes}

To unveil the details of the electron transfers in $\mathbf{R u}_{2} \mathbf{F e}_{3}$ and $\mathbf{R u}_{2} \mathbf{M n}_{3}, \mathrm{UV}$-vis absorption spectroscopic and UV-vis spectroelectrochemical (UV-SEC) measurements were taken. The UV-vis absorption spectra of the heterometallic pentanuclear complexes before oxidation are shown in Supplementary Figure 4. All the complexes exhibited intense bands in the visible region (Supplementary Table 7), and these bands can be assigned to the metal-to-ligand charge transfer (MLCT) transitions of the ruthenium centres by comparison with the UV-vis absorption spectra of the corresponding homometallic complexes (Supplementary Figure 4b).

Initially, we performed UV-SEC experiments with $\mathbf{R u}_{2} \mathbf{Z n}_{3}$ and $\mathbf{R} \mathbf{u}_{2} \mathbf{C o 3}_{3}$. The intensities of the MLCT bands of these complexes decreased in a stepwise manner with isosbestic points corresponding to the first and second oxidation steps (Figure 3 and Supplementary Figure 5, and Supplementary Table 8). To probe the oxidation processes in detail, the bleaching ratios of the MLCT bands were calculated ${ }^{45}$. The bleaching ratios of the MLCT bands of $\mathbf{R u}_{2} Z_{3} n_{3}$ and $\mathbf{R u}_{2} \mathrm{Cos}_{3}$ for the first oxidation step were calculated to be 46.6 and $53.9 \%$, respectively, and those for the second oxidation step were 53.4 and $46.1 \%$ (Table 1). This result indicates that each ruthenium centre in these complexes undergoes a one-electron oxidation, which is consistent with the electrochemical 
measurements (vide supra). Based on these results, it is revealed that the observed MLCT bands can provide information on the oxidation states of the ruthenium centres due to the drastic changes in the intensity of the bands as a response to the oxidation states of the ruthenium centres.
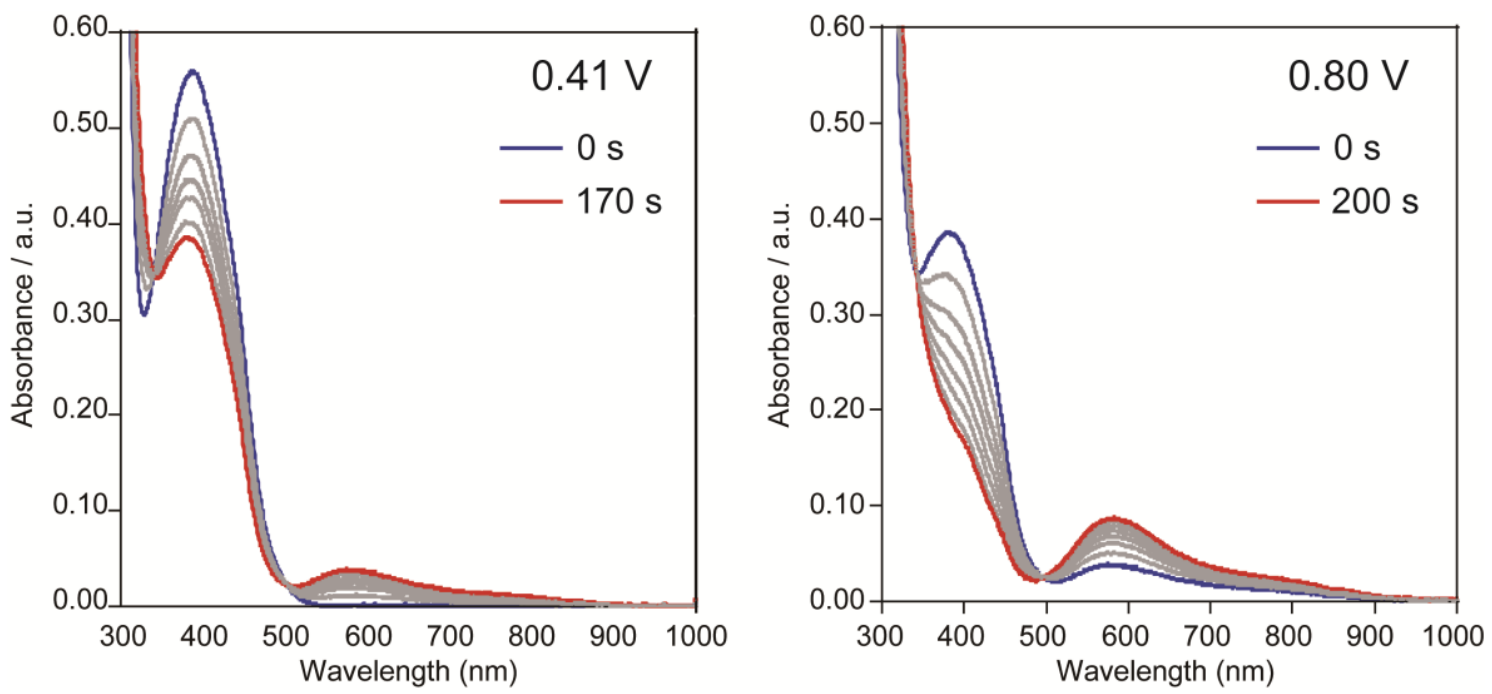

Figure 3 | UV-Vis absorption spectral changes of $\mathbf{R u}_{2} \mathbf{Z n}_{3}(0.1 \mathrm{mM})$ upon oxidation in 0.1 M TBAP/MeCN. Applied potentials are (left) 0.42 and (right) $0.80 \mathrm{~V}$ (vs. Fc/Fc ${ }^{+}$, respectively. All measurements were performed under an Ar atmosphere. 
Table 1 Summary of the estimation of the bleaching ratios of the MLCT bands in a series of heterometallic pentanuclear complexes.

\begin{tabular}{|c|c|c|c|c|c|c|c|}
\hline complex & $\begin{array}{c}\lambda_{\max }(\mathrm{MLCT}) \\
/ \mathrm{nm}\end{array}$ & & $\begin{array}{c}\text { before oxidation } \\
\quad(k=0)\end{array}$ & $\begin{array}{c}\text { 1st oxidation } \\
\quad(k=1) \\
\end{array}$ & $\begin{array}{l}\text { 2nd oxidation } \\
\qquad(k=2)\end{array}$ & $\begin{array}{l}\text { 3rd oxidation } \\
\quad(k=3)\end{array}$ & $\begin{array}{l}\text { 4th oxidation } \\
\quad(k=4) \\
\end{array}$ \\
\hline \multirow{4}{*}{$\mathbf{R} \mathbf{u}_{2} \mathbf{Z n} \mathbf{n}_{3}$} & \multirow{4}{*}{394} & $A_{\mathrm{n}}$ & 0.553 & 0.377 & 0.175 & - & - \\
\hline & & $A_{\mathrm{n}}^{\prime}$ & 0.379 & 0.202 & 0.000 & - & - \\
\hline & & $\Delta A_{\mathrm{n}}^{\prime}$ & - & 0.177 & 0.202 & - & - \\
\hline & & $\begin{array}{l}\text { bleaching ratio of } \\
\text { MLCT band } / \%\end{array}$ & - & 46.6 & 53.4 & - & - \\
\hline \multirow{4}{*}{$\mathrm{Ru}_{2} \mathrm{Co}_{3}$} & \multirow{4}{*}{389} & $A_{\mathrm{n}}$ & 0.494 & 0.355 & 0.237 & - & - \\
\hline & & $A_{\mathrm{n}}^{\prime}$ & 0.257 & 0.118 & 0.000 & - & - \\
\hline & & $\Delta A_{\mathrm{n}}^{\prime}$ & - & 0.138 & 0.118 & - & - \\
\hline & & $\begin{array}{l}\text { bleaching ratio of } \\
\text { MLCT band } 1 \%\end{array}$ & - & 53.9 & 46.1 & - & - \\
\hline \multirow{4}{*}{$\mathbf{R u}_{2} \mathbf{F e}_{3}$} & \multirow{4}{*}{390} & $A_{\mathrm{n}}$ & 0.523 & 0.510 & 0.460 & 0.221 & 0.186 \\
\hline & & $A_{\mathrm{n}}^{\prime}$ & 0.337 & 0.324 & 0.275 & 0.035 & 0.000 \\
\hline & & $\Delta A_{\mathrm{n}}^{\prime}$ & - & 0.013 & 0.049 & 0.240 & 0.035 \\
\hline & & $\begin{array}{l}\text { bleaching ratio of } \\
\text { MLCT band } 1 \%\end{array}$ & - & 3.9 & 14.6 & 71.1 & 10.4 \\
\hline \multirow{4}{*}{$\mathbf{R u}_{2} \mathbf{M n} \mathbf{n}_{3}$} & \multirow{4}{*}{380} & $A_{\mathrm{n}}$ & 0.504 & 0.533 & 0.524 & 0.316 & 0.236 \\
\hline & & $A_{\mathrm{n}}^{\prime}$ & 0.268 & 0.297 & 0.288 & 0.080 & 0.000 \\
\hline & & $\Delta A_{\mathrm{n}}^{\prime}$ & - & -0.029 & 0.009 & 0.208 & 0.080 \\
\hline & & $\begin{array}{l}\text { bleaching ratio of } \\
\text { MLCT band } / \%\end{array}$ & - & -10.7 & 3.2 & 77.6 & 30.0 \\
\hline
\end{tabular}


Subsequently, UV-SEC experiments on $\mathbf{R} \mathbf{u}_{2} \mathbf{F e} 3$ were performed by oxidizing the complex at $0.40,0.61,1.00$, and $1.30 \mathrm{~V}$. In all steps, spectral changes with clear isosbestic points were observed (Figure 4 and Supplementary Table 8), which suggests the formation of a single product at each oxidation step. In the first and the second steps, the bleaching of the MLCT band was not significant. In contrast, in the third step, the intensity of the MLCT band decreased drastically. In the fourth step, the bleaching of the MLCT band was again rather small. The bleaching ratios of the MLCT band in these steps were 3.9 (1st), 14.6 (2nd), 71.1 (3rd), and 10.4 (4th)\% (Table 1). These observations imply that the two $\mathrm{Ru}$ ions in $\mathbf{R u 2} \mathbf{F e} 3$ were simultaneously oxidized in the third oxidation step, although the results of the electrochemical measurements indicate that this step is a oneelectron oxidation process (vide supra). 

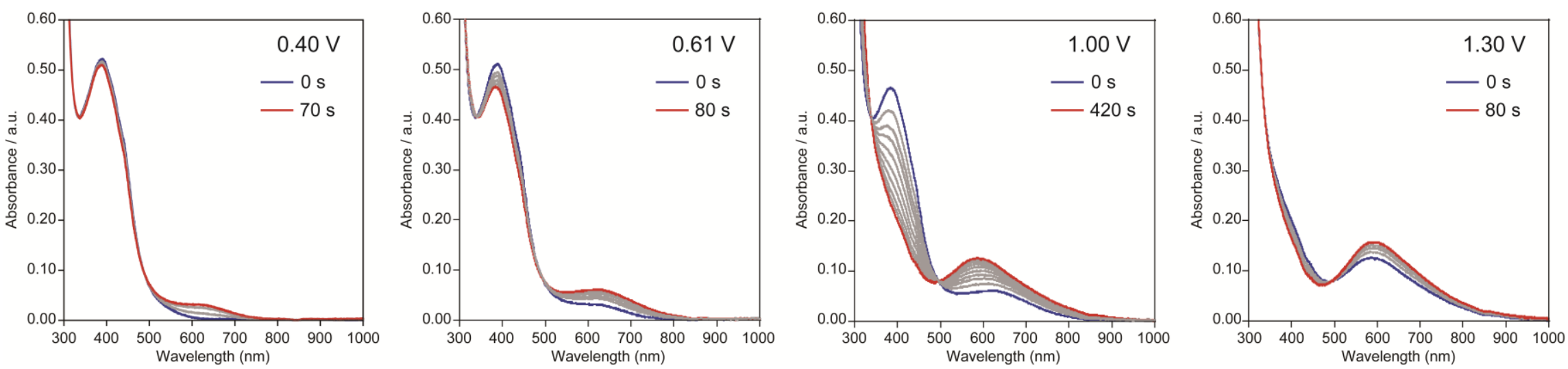

Figure 4 | UV-Vis absorption spectral changes of $\mathbf{R u}_{2} \mathbf{F e}_{3}(0.1 \mathrm{mM})$ upon oxidation in $0.1 \mathrm{M}$ TBAP/MeCN. Applied potentials are 0.40 ,

$0.61,1.00$ and $1.3 \mathrm{~V}\left(v s . \mathrm{Fc} / \mathrm{Fc}^{+}\right)$, respectively. All measurements were performed under an $\mathrm{Ar}$ atmosphere. 
A reasonable interpretation of the aforementioned discrepancy in the results of the UV-SEC and electrochemical measurements is provided by comparing the redox behaviours of $\mathbf{R u}_{2} \mathbf{F e}_{3}$ with those of $\mathbf{F e} 5$. We previously clarified the redox behaviours of Fes by UV-SEC measurements, ${ }^{57} \mathrm{Fe}$ Mössbauer spectroscopy, and quantum chemical calculations $^{25}$ (Scheme 3, top). A notable electron transfer process was observed in the second oxidation. In this step, the one-electron oxidation of the overall complex induces the reduction of one of the $\mathrm{Fe}^{\mathrm{III}}$ ions in the triangular core to the $\mathrm{Fe}^{\mathrm{II}}$ state (a "reductionupon-oxidation" process). Simultaneously, the two iron atoms in the apical positions were oxidized to the $\mathrm{Fe}^{\mathrm{III}}$ state, and the apparent change in the overall charge due to this oxidation step is one. In other words, the reduction of the triangular core upon oxidation of the complex allows the simultaneous oxidation of the two metal centres at the apical positions. Therefore, our results suggest a similar reduction-upon-oxidation process is occurring in $\mathbf{R u}_{2} \mathbf{F e}$, although the third oxidation step involves the corresponding reaction (Scheme 3, 2nd row). These results indicate that the substitution of iron ions for ruthenium ions can change the step corresponding to the reduction-upon-oxidation process.

For $\mathbf{R u}_{2} \mathbf{M n}_{3}$, the UV-vis absorption spectra changed in a manner similar to that of $\mathbf{R u}_{2} \mathbf{F e}_{3}$; bleaching of the MLCT band was observed only at the third oxidation step 
(Supplementary Figure 6). Therefore, $\mathbf{R u}_{2} \mathbf{M n}_{3}$ can also undergo a reduction-uponoxidation process at the triangular core (Scheme 3, bottom). Note that the oxidation of the relevant homometallic complex, Mn5, does not involve such a process ${ }^{36}$ (Scheme 3, 3rd row). Therefore, the unique electron transfer process can be induced by the installation of ruthenium ions in the case of a manganese-based complex.

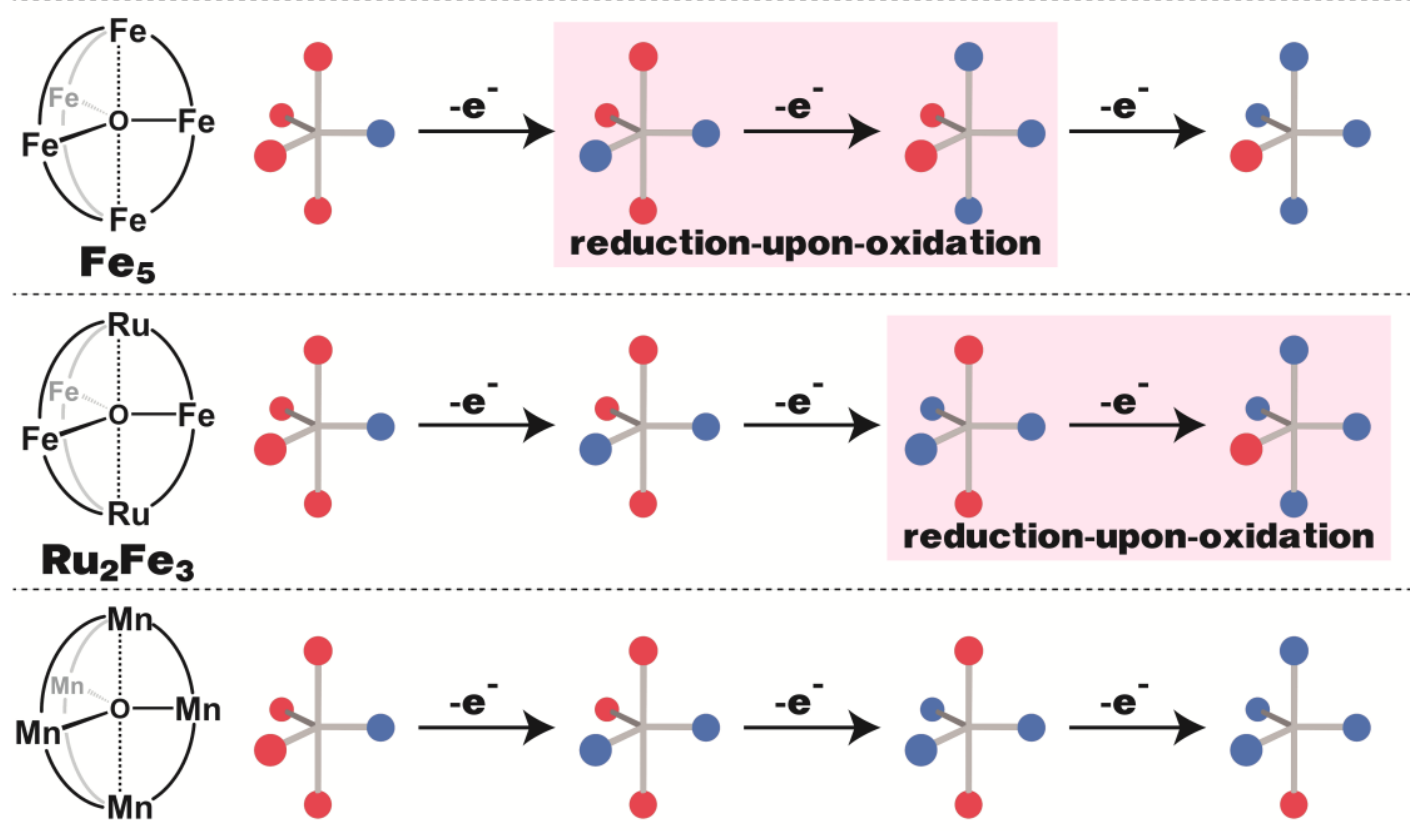

$M \mathbf{n}_{5}$

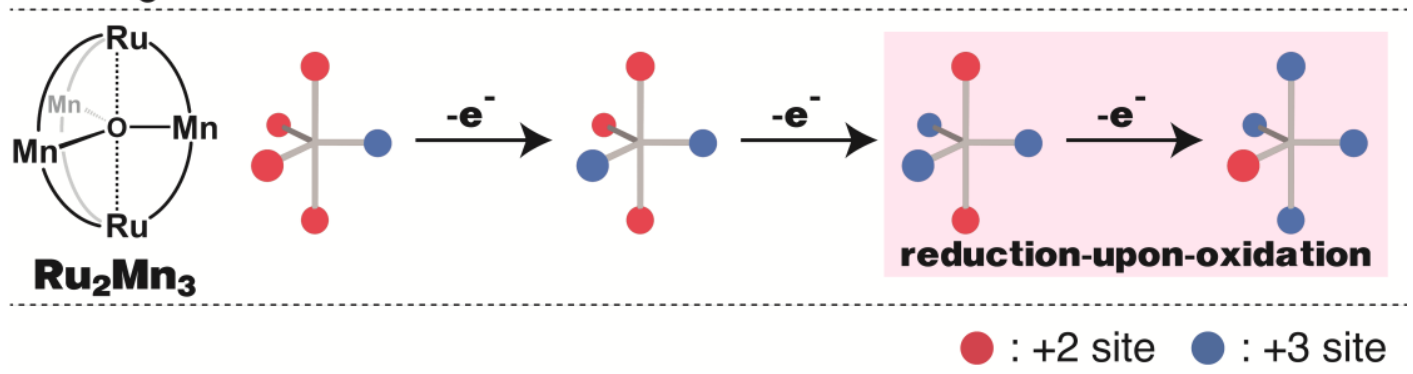

Scheme 3 | Summary of electron transfer processes of $\mathbf{F e}_{5}{ }^{25}, \mathbf{R u}_{2} \mathbf{F e}_{3}, \mathbf{M n}_{5}{ }^{36}$ and $\mathbf{R u}_{2} \mathbf{M n}_{3}$.

Metal centres with +2 and +3 oxidation states are represented in red and blue circles, respectively. 


\section{Key factors controlling the electron transfers in pentanuclear metal complexes}

To verify the origin of the aforementioned unique electron transfer behaviour, the reduction-upon-oxidation process, we initially investigated the process which was observed in $\mathbf{R u}_{2} \mathbf{F e}_{3}$ and $\mathbf{R} \mathbf{u}_{2} \mathbf{M n}_{3}$. Hereafter, the following notation, (x, y), will be used to describe the distribution of oxidation states of metal centres. $\mathrm{x}$ and $\mathrm{y}$ represent the sum of the charges of metal ions at apical positions $\left(\mathrm{M}_{\mathrm{api}}\right)$ and a triangular core $\left(\mathrm{M}_{\text {core }}\right)$, respectively (for instance, $(4,6)$ corresponds to the $\mathrm{M}_{\text {api }}{ }_{2}{ }_{2} \mathrm{M}_{\text {core }}{ }_{3}$ state). With this notation, the reduction-upon-oxidation process observed in $\mathbf{R u}_{2} \mathbf{F} \mathbf{e}_{3}$ and $\mathbf{R} \mathbf{u}_{2} \mathbf{M n}_{3}$ can be described as $(4,9) \rightarrow(6,8)$ process. However, in the oxidation reaction of $(4,9)$, there should be another possibility in addition to the observed $(4,9) \rightarrow(6,8)$ process; the formation of $(5,9)$ by the oxidation of $(4,9)$ without the reduction-upon-oxidation process (Figure 5a). 
a

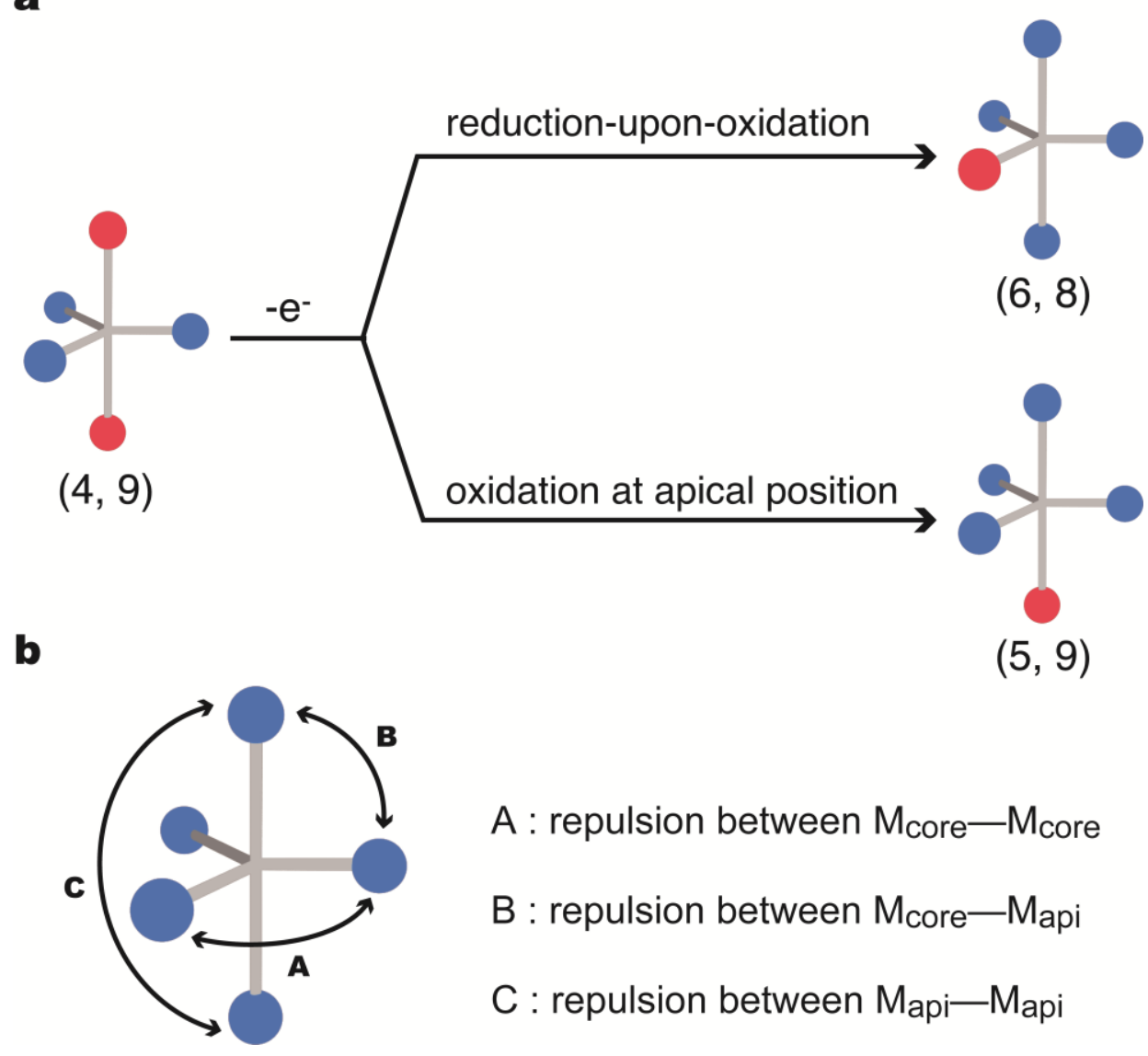

Figure $5 \mid$ (a) Two possible oxidation pathways of $(4,9)$. Metal centres with +2 and +3 oxidation states are represented in red and blue circles, respectively. (b) Schematic illustration of the electrostatic repulsion between metal centres in the pentanuclear metal complex system. 
The exclusive formation of $(6,8)$ instead of $(5,9)$ can be understood by considering the electrostatic repulsion between metal centres. As shown in Figure 5b, there exist three manners of electrostatic repulsion (denoted A, B, and C) between metal centres. $\mathrm{A}, \mathrm{B}$, and $\mathrm{C}$ correspond to the electrostatic repulsion between $\mathrm{M}_{\mathrm{core}}-\mathrm{M}_{\text {core, }}$ $\mathrm{M}_{\mathrm{core}}-\mathrm{M}_{\mathrm{api}}$, and $\mathrm{M}_{\mathrm{api}}-\mathrm{M}_{\mathrm{api}}$, respectively. In general, the energy of electrostatic repulsion $(E)$ between two point charges $\left(\mathrm{q}_{1}\right.$ and $\left.\mathrm{q}_{2}\right)$ can be expressed in terms of columbic potential by using the following equation (eq. 1).

$$
E=\frac{1}{4 \pi \varepsilon_{0}} \frac{q_{1} q_{2}}{r_{12}} \ldots \ldots \ldots \ldots(\text { eq. } 1)
$$

where $\varepsilon_{0}$ is vacuum permittivity and $r_{12}$ represents the distance between point charges.

In our system, we roughly estimated the total columbic potentials of two states, $(6,8)$ and $(5,9)$, based on the assumption that the atomic charges of metal centres are constant if the oxidation states are identical. Under this assumption, the atomic charges of $\mathrm{M}(\mathrm{II})$ and $\mathrm{M}(\mathrm{III})$ centres can be expressed as $\mathrm{q}^{\mathrm{II}}$ and $\mathrm{q}^{\mathrm{III}}$, regardless of the difference in the identity of metal ions and the coordination environment around metal ions. As a result, the energy of electrostatic repulsion between two metal centres $\left(E(\mathrm{X})_{m, k}\right)$ is expressed as follows (eq. 2).

$$
E(X)_{m, k}=\frac{1}{4 \pi \varepsilon_{0}} \frac{q_{m} q_{k}}{r_{X}} \cdots \cdots \cdots(e q .2)
$$


where $\mathrm{X}=\mathrm{A}, \mathrm{B}$, or $\mathrm{C}, m$ and $k$ represent the oxidation states of metal centres and $r_{\mathrm{x}}$ is the distance between metal centres.

The total energies of $(6,8)$ and $(5,9)$ states $\left(E_{\text {total }}(6,8)\right.$ and $\left.E_{\text {total }}(5,9)\right)$ can be calculated as follows.

$$
\begin{aligned}
& E_{\text {total }}(6,8)=E(\mathrm{~A})_{3,3}+2 E(\mathrm{~A})_{3,2}+4 E(\mathrm{~B})_{3,3}+2 E(\mathrm{~B})_{3,2}+E(\mathrm{C})_{3,3} \\
& E_{\text {total }}(5,9)=3 E(\mathrm{~A})_{3,3}+3 E(\mathrm{~B})_{3,3}+3 E(\mathrm{~B})_{3,2}+E(\mathrm{C})_{3,2}
\end{aligned}
$$

Therefore, the energy difference between these two states is estimated as follows.

$$
\begin{aligned}
& E_{\text {total }}(6,8)-E_{\text {total }}(5,9) \\
& =-2 E(\mathrm{~A})_{3,3}+2 E(\mathrm{~A})_{3,2}+E(\mathrm{~B})_{3,3}-E(\mathrm{~B})_{3,2}+E(\mathrm{C})_{3,3}-E(\mathrm{C})_{3,2} \\
& =\frac{1}{4 \pi \varepsilon_{0}} q_{\mathrm{III}}\left(q_{\mathrm{III}}-q_{\mathrm{II}}\right)\left(\frac{1}{r_{B}}+\frac{1}{r_{C}}-\frac{2}{r_{\mathrm{A}}}\right)<0 \\
& \because q_{\mathrm{III}}>q_{\mathrm{II}}>0, \quad r_{C}>r_{B}>r_{A}>0
\end{aligned}
$$

As a result, $E_{\text {total }}(6,8)$ becomes smaller than $E_{\text {total }}(5,9)$. In other words, $(6,8)$ has less electrostatic repulsion compared to $(5,9)$, and thus should energetically be favoured. 
Similarly, in the $(4,8) \rightarrow(6,7)$ process, which occurs in Fes, is discussed. The oxidation of $(4,8)$ can potentially generate three kinds of valence tautomers, $(6,7),(5,8)$, and $(4,9)$. The Etotal of these states can be estimated in the same manner as described above (see the SI (P. S23-24) for details), and the order of the values of $E_{\text {total }}$ for these states is $E_{\text {total }}(6,7)<E_{\text {total }}(5,8)<E_{\text {total }}(4,9)$. Therefore, the relative stabilities of these three valence tautomers are in the order of $(6,7)>(5,8)>(4,9)$, and the formed species is estimated to be more stable than the other valence tautomers, $(4,9)$ and $(5,8)$. These results indicate that the reduction-upon-oxidation process reduces the electrostatic repulsion and contributes to the formation of more energetically favourable species.

However, the explanation based solely on the effect of electrostatic interactions cannot explain the difference in the electron transfer processes between $\mathbf{F e}_{5}, \mathbf{R u}_{2} \mathrm{Fe}_{3}$, $\mathbf{R u}_{2} \mathbf{M n}_{3}$, and Mn5. The reduction-upon-oxidation process of $\mathbf{F e} 5$ occurs in the oxidation of $(4,8)$, that of $\mathbf{R u}_{2} \mathbf{F e}_{3}$ and $\mathbf{R u}_{2} \mathbf{M n}_{3}$ is in the oxidation of $(4,9)$, and Mn5 does not exhibit a reduction-upon-oxidation process (Scheme 3). It seems that the emergence of reduction-upon-oxidation processes in pentanuclear complexes is largely dependent on $\mathrm{M}_{\text {api }} ; \mathrm{Fe}_{\text {api }}$ is better able than $\mathrm{Ru}_{\text {api }}$ to induce a reduction-upon-oxidation process, and $\mathrm{Mn}_{\text {api }}$ hardly induces this process. In principle, the reduction-upon-oxidation process of the triangular core should be accompanied by the oxidation of $\mathrm{M}_{\text {api. }}$. Therefore, the redox 
potentials of $\mathrm{M}_{\mathrm{api}}$ should influence the occurrence of reduction-upon-oxidation process. As evidenced by the CV and UV-SEC measurements, the redox potentials that involve the oxidation of $\mathrm{M}_{\text {api }}$ are largely dependent on the identity of $\mathrm{M}_{\mathrm{api}} ; \mathrm{Fe} 5(0.29 \mathrm{~V}), \mathbf{R} \mathbf{u}_{2} \mathbf{F e} 3$ (0.75 V), $\operatorname{Ru}_{2} \mathbf{M n}_{3}(0.78 \mathrm{~V})$, and Mns (1.11 and 1.24 V). These results indicate that the potential required to oxidize $\mathrm{M}_{\text {api }}$ may be in the order of $\mathrm{Fe}_{\mathrm{api}}<\mathrm{Ru}_{\text {api }}<\mathrm{Mn}_{\text {api }}$. To further confirm this explanation, we compared the redox potentials of several mononuclear metal complexes that contain $\mathrm{Fe}^{2+}, \mathrm{Ru}^{2+}$ or $\mathrm{Mn}^{2+}$ as the metal ion and six nitrogen donor atoms ${ }^{46-}$ 51, as shown in Supplementary Table 9. These complexes are representative hexacoordinate metal centres with octahedral geometry and can thus be regarded as model compounds that mimic the structure around the $\mathrm{M}_{\text {api }}$ centres of our pentanuclear complexes. In these complexes, the order of the redox potentials is $\mathrm{Fe}<\mathrm{Ru}<\mathrm{Mn}$, which is consistent with our pentanuclear system. Therefore, it is reasonable to consider that the redox potentials of $\mathrm{M}_{\mathrm{api}}$ are also an essential factor in determining the electron transfer behaviour of the pentanuclear metal complexes. The reduction-upon-oxidation process, which generates the species with the least electrostatic repulsion, is suppressed when the potential is not enough to oxidize $\mathrm{M}_{\text {api }}$.

We could explain all the electron transfer processes in which the reduction-uponoxidation process is suppressed based on the consideration discussed above: (i) the 
formation of $(4,8)$ instead of $(6,6)$ by the oxidation of $(4,7)$ in $\mathbf{F e} 5, \mathbf{R u}_{2} \mathbf{F e}_{3}, \mathbf{R u}_{2} \mathbf{M n}_{3}$, and Mn5 (Supplementary Figure 8a); (ii) the formation of $(4,9)$ instead of $(6,7)$ by the oxidation of $(4,8)$ in $\mathbf{R u}_{2} \mathbf{F e} 3, \mathbf{R} \mathbf{u}_{2} \mathbf{M n}_{3}$, and $\mathbf{M n}_{5}$ (Supplementary Figure 8b); and (iii) the formation of $(5,9)$ instead of $(6,8)$ by the oxidation of $(4,9)$ in Mns (Supplementary Figure $8 \mathrm{c})$. In the oxidation of $(4,7)$, the oxidation of the core proceeds in all four complexes because the potentials are not enough to oxidize $\mathrm{M}_{\text {api }}$. In the oxidation of (4, 8), Fes can undergo reduction-upon-oxidation process to minimize electrostatic repulsion because $\mathrm{Fe}_{\text {api }}$ is readily oxidized. However, for $\mathbf{R u}_{2} \mathbf{F e} 3$, $\mathbf{R} \mathbf{u}_{2} \mathbf{M n}_{3}$, and $\mathbf{M n}_{5}$, the reductionupon-oxidation process is suppressed because $\mathrm{Ru}_{\text {api }}$ and $\mathrm{Mn}_{\text {api }}$ are hardly oxidized in this potential region. In the oxidation of $(4,9), \mathbf{R u}_{2} \mathbf{F} \mathbf{e}_{3}$ and $\mathbf{R} \mathbf{u}_{2} \mathbf{M n} 3$ can undergo reductionupon-oxidation process by the oxidation of $\mathrm{Ru}_{\text {api }}$ and the reduction of the $\mathrm{M}_{\text {core. }}$ In contrast, in the case of Mns, the reduction-upon-oxidation process cannot proceed because the high potential required to oxidize $\mathrm{Mn}_{\text {api }}$ prevents the reduction of $\mathrm{Mn}_{\text {core }}$ in this potential range. As a result, $(5,9)$ forms instead of $(6,8)$ in this oxidation step of Mns. Therefore, the electrostatic repulsion between the metal centres and the ease of the oxidation of $\mathrm{M}_{\text {api }}$ are the dominant factors that determine the reduction-upon-oxidation processes of these pentanuclear complexes. These results clearly demonstrate that complicated redox 
behaviours of multinuclear metal complexes can be rationally understood by systematic investigation. 


\section{Conclusion}

In this study, we successfully constructed a series of pentanuclear metal complexes with the same molecular framework. The development of a stepwise synthetic route allowed the on-demand installation of two kinds of metal ions into the penta-nuclear scaffold. The distribution of oxidation states in all the complexes, which are altered during the redox reactions, was clarified based on the results of single-crystal X-ray diffraction, electrochemical measurements, UV-vis absorption spectroscopy, and UV-SEC measurements. As a result, a general picture of the redox reactions in the system was unveiled as shown in Supplementary Scheme 1, and unique electron transfer behaviours, in which a metal centre is reduced during oxidation of the complex, were discovered. Furthermore, the two factors that impact the redox behaviours of the complexes were determined. Collectively, our systematic investigation of a series of pentanuclear complexes demonstrated that the flexible transfer of electrons in clustered redox-active sites could be programmed by the precise arrangement of the metal ions. 


\section{References}

1. Chakrabarty, R., Mukherjee, P. S. \& Stang, P. J. Supramolecular coordination: selfassembly of finite two- and three-dimensional ensembles. Chem. Rev. 111, 68106918 (2011).

2. Chen, L.-J., Yang, H.-B. \& Shionoya, M. Chiral metallosupramolecular architectures. Chem. Soc. Rev. 46, 2555-2576 (2017).

3. Sun, Q.-F., Iwasa, J., Ogawa, D., Ishido, Y., Sato, S., Ozeki, T., Sei, Y., Yamaguchi, K. \& Fujita, M. Self-assembled $\mathrm{M}_{24} \mathrm{~L}_{48}$ polyhedra and their sharp structural switch upon subtle ligand variation. Science 328, 1144-1147 (2010).

4. Kanady, J. S., Tsui, E. Y., Day, M. W. \& Agapie, T. A synthetic model of the $\mathrm{Mn}_{3} \mathrm{Ca}$ subsite of the oxygen-evolving complex in photosystem II. Science 333, 733-736 (2011).

5. Lim, S. H., Su, Y. \& Cohen, S. M. Supramolecular tetrahedra of phosphines and coinage metals. Angew. Chem. Int. Ed. 51, 5106-5109 (2012).

6. Horiuchi, S., Tachibana, Y., Yamashita, M., Yamamoto, K., Masai, K., Takase, K., Matsutani, T., Kawamata, S., Kurashige, Y., Yanai, T. \& Murahashi, T. Multinuclear metal-binding ability of a carotene. Nat. Commun. 6, 6742 (2015).

7. Teramoto, M., Iwata, K., Yamaura, H., Kurashima, K., Miyazawa, K., Kurashige, Y., Yamamoto, K. \& Murahashi, T. Three-dimensional sandwich nanocubes composed of 13-atom palladium core and hexakis-carbocycle shell. J. Am. Chem. Soc. 140, 12682-12686 (2018).

8. Fujita, D., Ueda, Y., Sato, S., Mizuno, N., Kumasaka, T. \& Fujita, M. Self-assembly of tetravalent Goldberg polyhedra from 144 small components. Nature 540, 563-566 (2016).

9. Ube, H., Endo, K., Sato, H. \& Shionoya, M. Synthesis of hetero-multinuclear metal complexes by site-selective redox switching and transmetalation on a homomultinuclear complex. J. Am. Chem. Soc. 141, 10384-10389 (2019).

10. Zhu, B.-H., Shibata, Y., Muratsugu, S., Yamanoi, Y. \& Nishihara, H. A cyclic hexanuclear heterometalladithiolene cluster $\quad\left[\left\{(\mathrm{Cp} * \mathrm{Rh})_{2} \mathrm{Mo}(\mu-\right.\right.$ $\left.\left.\mathrm{CO})_{2}(\mathrm{CO})\right\}_{2}\left(\mathrm{~S}_{2} \mathrm{C}_{6} \mathrm{H}_{2} \mathrm{~S}_{2}\right)_{2}\right]$ with two $\pi$-conjugated $\mathrm{S}_{2} \mathrm{C}_{6} \mathrm{~S}_{2}$ bridges: synthesis, crystal structure, and properties. Angew. Chem. Int. Ed. 48, 3858-3861 (2009).

11. Ismayilov, R. H., Wang, W.-Z., Lee, G.-H., Yeh, C.-Y., Hua, S.-A., Song, Y., Rohmer, M.-M., Bénard, M. \& Peng, S.-M. Two linear undecanickel mixed-valence complexes: increasing the size and the scope of the electronic properties of nickel metal strings. Angew. Chem. Int. Ed. 50, 2045-2048 (2011). 
12. Muratsugu, S., Sodeyama, K., Kitamura, F., Tsukada, S., Tada, M., Tsuneyuki, S. \& Nishihara, $\mathrm{H}$. Normal and inverted redox potentials and structural changes tuned by medium effects in $\left[\mathrm{M}_{2} \mathrm{Mo}\left(\eta^{5}-\mathrm{C}_{5} \mathrm{Me}_{5}\right)_{2}\left(\mathrm{~S}_{2} \mathrm{C}_{6} \mathrm{H}_{4}\right)_{2}(\mathrm{CO})_{2}\right](\mathrm{M}: \mathrm{Co}, \mathrm{Rh})$. Chem. Sci. 2, 1960-1968 (2011).

13. Murahashi, T., Shirato, K., Fukushima, A., Takase, K., Suenobu, T., Fukuzumi, S., Ogoshi, S. \& Kurosawa, H. Redox-induced reversible metal assembly through translocation and reversible ligand coupling in tetranuclear metal sandwich frameworks. Nat. Chem. 4, 52-58 (2012).

14. Tsui, E. Y., Tran, R., Yano, J. \& Agapie, T. Redox-inactive metals modulate the reduction potential in heterometallic manganese-oxido clusters. Nat. Chem. 5, 293-299 (2013).

15. Rausch, B., Symes, M. D., Chisholm, G. \& Cronin, L. Decoupled catalytic hydrogen evolution from a molecular metal oxide redox mediator in water splitting. Science 345, 1326-1330 (2014).

16. Sessoli, R., Tsai, H.-L., Schake, A. R., Wang, S., Vincent, J. B., Folting, K., Gatteschi, D., Christou, G. \& Hendrickson, D. N. High-spin molecules: $\left[\mathrm{Mn}_{12} \mathrm{O}_{12}\left(\mathrm{O}_{2} \mathrm{CR}\right)_{16}\left(\mathrm{H}_{2} \mathrm{O}\right)_{4}\right]$. J. Am. Chem. Soc. 115, 1804-1816 (1993).

17. Sessoll, R., Gatteschi, D., Caneschi, A. \& Novak, M. A. Magnetic bistability in a metal-ion cluster. Nature 365, 141-143 (1993).

18. Matsumoto, T., Newton, G. N., Shiga, T., Hayami, S., Matsui, Y., Okamoto, H., Kumai, R., Murakami, Y. \& Oshio, H. Programmable spin-state switching in a mixedvalence spin-crossover iron grid. Nat. Commun. 5, 3865 (2014).

19. Yam, V. W.-W., Au, V. K.-M. \& Leung, S. Y.-L. Light-emitting self-assembled materials based on $\mathrm{d}^{8}$ and $\mathrm{d}^{10}$ transition metal complexes. Chem. Rev. 115, 7589-7728 (2015).

20. Rohacova, J. \& Ishitani, O. Rhenium(I) trinuclear rings as highly efficient redox photosensitizers for photocatalytic $\mathrm{CO}_{2}$ reduction. Chem. Sci. 7, 6728-6739 (2016).

21. Buchwalter, P., Rosé, J. \& Braunstein, P. Multimetallic catalysis based on heterometallic complexes and clusters. Chem. Rev. 115, 28-126 (2015).

22. Arnold, P. L., Patel, D., Wilson, C. \& Love, J. B. Reduction and selective oxo group silylation of the uranyl dication. Nature 451, 315-317 (2008).

23. Arnold, P. L., Jones, G. M., Odoh, S. O., Schreckenbach, G., Magnani, N. \& Love, J. B. Strongly coupled binuclear uranium-oxo complexes from uranyl oxo rearrangement and reductive silylation. Nat. Chem. 4, 221-227 (2012). 
24. Ogo, S., Ichikawa, K., Kishima, T., Matsumoto, T., Nakai, H., Kusaka, K. \& Ohhara, $\mathrm{T}$. A functional [NiFe]hydrogenase mimic that catalyzes electron and hydride transfer from $\mathrm{H}_{2}$. Science 339, 682-684 (2013).

25. Okamura, M., Kondo, M., Kuga, R., Kurashige, Y., Yanai, T., Hayami, S., Praneeth, V. K. K., Yoshida, M., Yoneda, K., Kawata, S. \& Masaoka, S. A pentanuclear iron catalyst designed for water oxidation. Nature 530, 465-468 (2016).

26. Jiang, X., Li, J., Yang, B., Wei, X.-Z., Dong, B.-W., Kao, Y., Huang, M.-Y., Tung, C.H. \& Wu, L.-Z. A bio-inspired $\mathrm{Cu}_{4} \mathrm{O}_{4}$ cubane: effective molecular catalysts for electrocatalytic water oxidation in aqueous solution. Angew. Chem. Int. Ed. 57, 7850 -7854 (2018).

27. Lancaster, K. M., Roemelt, M., Ettenhuber, P., Hu, Y., Ribbe, M. W., Neese, F., Bergmann, U. \& DeBeer, S. X-ray emission spectroscopy evidences a central carbon in the nitrogenase iron-molybdenum cofactor. Science 334, 974-977 (2011).

28. Umena, Y., Kawakami, K., Shen, J.-R. \& Kamiya, N. Crystal structure of oxygenevolving photosystem II at a resolution of 1.9 A. Nature 473, 55-60 (2011).

29. Suga, M., Akita, F., Hirata, K., Ueno, G., Murakami, H., Nakajima, Y., Shimizu, T., Yamashita, K., Yamamoto, M., Ago, H. \& Shen, J.-R. Native structure of photosystem II at $1.95 \AA$ resolution viewed by femtosecond X-ray pulses. Nature 517, 99-103 (2015).

30. Brown, K, Tegoni, M., Prudêncio, M., Pereira, A. S., Besson, S., Moura, J. J., Moura, I. \& Cambillau, C. A novel type of catalytic copper cluster in nitrous oxide reductase. Nat. Struct. Biol. 7, 191-195 (2000).

31. Clemente-Juan, J. M., Coronado, E. \& Gaita-Ariño, A. Magnetic polyoxometalates: from molecular magnetism to molecular spintronics and quantum computing. Chem. Soc. Rev. 41, 7464-7478 (2012).

32. Hsu, L.-Y., Jin, B.-Y., Chen, C. \& Peng, S.-M., Reaction: new insights into molecular electronics, Chem 3, 373-379 (2017).

33. Busche, C., Vilá-Nadal, L., Yan, J., Miras, H. N., Long, D.-L., Georgiev, V. P., Asenov, A., Pedersen, R. H., Gadegaard, N., Mirza, M. M., Paul, D. J., Poblet, J. M. \& Cronin, L. Design and fabrication of memory devices based on nanoscale polyoxometalate clusters. Nature 515, 545-549 (2014).

34. Zhao, Y., Zhang, L., Li, X., Shi, Y., Ding, R., Teng, M., Zhang, P., Cao, C. \& Stang, P. J. Self-assembled ruthenium (II) metallacycles and metallacages with imidazolebased ligands and their in vitro anticancer activity. Proc. Natl. Acad. Sci. USA 116 (10), 4090-4098 (2019). 
35. Vinyard, D. J., Khan, S., Askerka, M., Batista, V. S. \& Brudvig, G. W. Energetics of the $\mathrm{S}_{2}$ state spin isomers of the oxygen-evolving complex of photosystem II. J. Phys. Chem. B 121, 1020-1025 (2017).

36. Romain, S., Rich, J., Sens, C., Stoll, T., Benet-Buchholz, J., Llobet, A., Rodriguez, M., Romero, I., Clérac, R., Mathonière, C., Duboc, C., Deronzier, A. \& Collomb, M.N. Multireversible redox processes in pentanuclear bis(triple-helical) manganese complexes featuring an oxo-centered triangular $\left\{\mathrm{Mn}_{2}{ }_{2} \mathrm{Mn}^{\mathrm{III}}\left(\mu_{3}-\mathrm{O}\right)\right\}^{5+}$ or $\left\{\mathrm{Mn}^{\mathrm{II}} \mathrm{Mn}^{\mathrm{III}}{ }_{2}\left(\mu_{3}-\mathrm{O}\right)\right\}^{6+}$ core wrapped by two $\left\{\mathrm{Mn}_{2}{ }_{2}(\mathrm{bpp})_{3}\right\}^{-}$. Inorg. Chem. 50, 84278436 (2011).

37. Gouré, E., Gerey, B., Clémancey, M., Pécaut, J., Molton, F., Latour, J.-M., Blondin, G. \& Collomb, M.-N. Intramolecular electron transfers thwart bistability in a pentanuclear iron complex. Inorg. Chem. 55, 9178-9186 (2016).

38. Yoneda, K., Adachi, K., Nishio, K., Yamasaki, M., Fuyuhiro, A., Katada, M., Kaizaki, S. \& Kawata, S. An $\left[\mathrm{Fe}^{\mathrm{II}}{ }_{3} \mathrm{O}\right]^{4+}$ core wrapped by two $\left[\mathrm{Fe}^{\mathrm{II}} \mathrm{L}_{3}\right]^{-}$units. Angew. Chem. Int. Ed. 45, 5459-5461 (2006).

39. Ishikawa, R., Nakano, M., Fuyuhiro, A., Takeuchi, T., Kimura, S., Kashiwagi, T., Hagiwara, M., Kindo, K., Kaizaki, S. \& Kawata, S. Construction of a novel topological frustrated system: a frustrated metal cluster in a helical space. Chem. Eur. J. 16, 11139-11144 (2010).

40. Praneeth, V. K. K., Kondo, M., Okamura, M., Akai, T., Izu, H. \& Masaoka, S. Pentanuclear iron catalysts for water oxidation: substituents provide two routes to control onset potential. Chem. Sci. 10, 4628-4639 (2019).

41. Akai, T., Kondo, M., Lee, S. K.; Izu, H., Enomoto, T.; Okamura, M.; Saga, Y. \& Masaoka, S. Effect of metal ion substitution on the catalytic activity of a pentanuclear metal complex. Dalton Trans., 49, 1384-1387 (2020).

42. Kondo, M. \& Masaoka, S. Pentanuclear scaffold: a molecular platform for smallmolecule conversions. Acc. Chem. Res., 53, 10, 2140-2151 (2020).

43. Kondo, M., Tatewaki, H. \& Masaoka, S. Design of molecular water oxidation catalysts with earthabundant metal ion. Chem. Soc. Rev., 50, 6790-6831 (2021).

44. Bellinger-Buckley, S., Chang, T.-C., Bag, S., Schweinfurth, D., Zhou, W., Torok, B., Sarkar, B., Tsai, M.-K. \& Rochford, J. Exploring the noninnocent character of electron rich $\pi$-extended 8-oxyquinolate ligands in ruthenium(II) bipyridyl complexes. Inorg. Chem. 53, 5556-5567 (2014).

45. The bleaching ratios of the MLCT bands upon oxidation were calculated by using the absorbance $\left(A_{k}\right)$ at the absorption maxima of the MLCT band $\left(\lambda_{\max }\right)$ of each heterometallic pentanuclear complex. Here, the state before oxidation is defined as $k$ 
$=0$, and the states generated by the first, second, third, and forth oxidations are defined as $k=1,2,3$, and 4, respectively. Initially, the absorbances of the fully oxidized state ( $A_{2}$ for $\mathbf{R} \mathbf{u}_{2} Z_{3}$ and $\mathbf{R} \mathbf{u}_{2} \mathbf{C o}_{3}$ and $A_{4}$ for $\mathbf{R} \mathbf{u}_{2} \mathbf{F e}_{3}$ and $\mathbf{R} \mathbf{u}_{2} \mathbf{M n}_{3}$ ) were used as the baseline and were subtracted from $A_{k}$, and the obtained values were defined as $A^{\prime}{ }_{k}$. Second, the decreases in the intensity of the MLCT bands upon oxidation were calculated as $\Delta A^{\prime}{ }_{k}=A^{\prime}{ }_{k-1}-A^{\prime}{ }_{k}$. Finally, the bleaching ratios of the MLCT bands were determined by using the following equation: $\left(\triangle A^{\prime}{ }_{k} / A^{\prime}{ }_{0}\right) \times 100,(k$ $=1-4)$. The results of the calculations are summarized in Table 1 .

46. Richert, S. A., Tsang, P. K. S. \& Sawyer, D. T. Ligand-centered redox processes for $\mathrm{MnL}_{3}, \mathrm{FeL}_{3}$, and $\mathrm{CoL}_{3}$ complexes $(\mathrm{L}=$ acetylacetonate, 8-quinolinate, picolinate, 2,2'-bipyridyl, 1,10-phenanthroline) and for their tetrakis(2,6dichlorophenyl)porphinato complexes [M(Por)]. Inorg. Chem. 28, 2471-2475 (1989).

47. Wallace, A. W., Murphy, Jr. W. R. \& Petersen, J. D. Electrochemical and photophysical properties of mono- and bimetallic ruthenium(II) complexes. Inorg. Chim. Acta. 166, 41-54 (1989).

48. Morrison, M. M. \& Sawyer D. T. Redox chemistry of the polyimine complexes of manganese (II), -(III), and -(IV) in acetonitrile. Inorg. Chem. 17, 333-337 (1978).

49. Wieghardt, K., Schmidt, W., Herrmann, W. \& Küppers, H.-J. Redox potentials of bis(1,4,7-triazacyclononane) complexes of some first transition series metals(II, III). Preparation of bis(1,4,7-triazacyclononane)nickel(III) perchlorate. Inorg. Chem. 22, 2953-2956 (1983).

50. Bernhard, P. \& Sargeson, A. M. Synthesis and properties of the Ru(tacn $)_{2}{ }^{3+/ 2+}$ couple and NMR study of the electron self-exchange (tacn =1,4,7-triazacyclononane). Inorg. Chem. 27, 2582-2587 (1988).

51. Alwis, D. C. L. D. \& Schultz, F. A. Metal-bis[poly(pyrazolyl)borate] complexes. Electrochemical, magnetic, and spectroscopic properties and coupled electrontransfer and spin-exchange reactions. Inorg. Chem. 42, 3616-3622 (2003). 
Supplementary Information is available in the online version of the paper.

Acknowledgements This work was supported by KAKENHI (17H06444 19H00903, and 20K21209 (S.M.), 17K19185, 17H05391, 19H04602, 19H05777, and 20H02754 (M.Ko.) and $17 \mathrm{H} 05390$ and 16K05735 (S.K.)) from the Japan Society for the Promotion of Science. This work was also supported by JST ACT-C, [grant no. JPMJCR12YH (M. Ko.)], JST PRESTO [grant no. JPMJPR20A4 (M. Ko.)] and JST CREST [grant no. JPMJCR20B6 (S. M.)], the Tokuyama Science Foundation (M.Ko.), Iketani Science and Technology Foundation (M.Ko.), Izumi Science and Technology Foundation (M.Ko.), and a research grant from The Mazda Foundation (M.Ko.) and the Central Research Institute of Fukuoka University, Grant Number 171011 (S.K.). The X-ray crystal structures of $\left[\mathbf{R u}\left(\mathbf{H b p p}_{3}\right]\left(\mathrm{PF}_{6}\right)_{2}, \mathbf{R u}_{2} \mathbf{Z n}_{3}\left(\mathrm{ClO}_{4}\right)_{3}, \mathbf{R u}_{2} \mathbf{C o}_{3}\left(\mathrm{PF}_{6}\right)_{3}, \mathbf{R u}_{2} \mathbf{F e}_{3}\left(\mathrm{ClO}_{4}\right)_{3}\right.$, and $\mathbf{R u}_{2} \mathbf{M n}_{3}\left(\mathrm{ClO}_{4}\right)_{3} \mathbf{Z n}_{5}\left(\mathrm{BF}_{4}\right)_{3}$ and $\operatorname{Cos}_{5}\left(\mathrm{BF}_{4}\right)_{3}$ have been deposited in the Cambridge Crystallographic Data Centre (CCDC 1949856-1949862, and 1949864).

Author Contributions H.I., M.Ko. and S.M. conceived of the project. H.I., M.Ko., M. O, S.K. and S.M. designed the experiments. H.I., M.O., S.-K.L., M.T., T.A., and M.Ka. performed the synthesis and characterization experiments. H.I. and M.Ko. performed the single-crystal X-ray diffraction studies. H.I. and V.K.K.P. performed electrochemical and UV-SEC measurements. H.I., M.Ko. and S.M. analysed the data and co-wrote the manuscript. All authors discussed the results and commented on the manuscript. H.I. and M.Ko. contributed equally to this work.

Author Information The authors declare no competing financial interests. Readers are welcome to comment on the online version of the paper. Correspondence and requests for materials should be addressed to S.M. (masaoka@chem.eng.osaka-u.ac.jp). 